\title{
Capital Social E ORÇAMENTO PARTICIPATIVO: UMA REVISÃO CRÍTICA DE ALGUNS AUTORES
}

\section{Cristiano das Neves Bodart ${ }^{1}$}

\begin{abstract}
Resumo
0 presente artigo busca discutir os possíveis impactos do capital social sobre a prática do Orçamento Participativo (OP). Embora a literatura tenha buscado enfocar os benefícios da ampliação do estoque de capital social (CS), objetivamos aqui apontar seus possíveis constrangimentos. Foram identificadas diversas possibilidades de geração de capital social negativo, as quais podem provocar, por meio da prática do OP, a manutenção das desigualdades sócio-espaciais, o desestímulo à participação, práticas clientelísticas, antagonismo de grupos, despolitização do processo de decisão, monopólio de grupos, a exclusão ou a autoexclusão dos indivíduos em tal prática, e outros constrangimentos apresentados neste artigo. Não objetivamos anular o mérito do OP, muito menos do capital social, apenas procuramos demonstrar que este é composto por duas faces opostas.
\end{abstract} Palavras-chave: Orçamento participativo. Capital social. Constrangimentos.

\footnotetext{
${ }^{1}$ Cientista Social/USC, Mestre em Planejamento Regional e Gestão de Cidades/UCAM. End. Eletrônico: cristianobodart@hotmail.com
} 


\title{
SOCIAL CAPITAL AND PARTICIPATORY BUDGETING: A CRITICAL REVIEW OF SELECTED AUTHORS
}

\begin{abstract}
The present article seeks to discuss the possible impact of social capital on the practice of Participatory Budgeting (PB). Although the literature has attempted to focus on the benefits of extending the stock of social capital (SC), we intend here to point out its possible iniquities. Diverse possibilities of the generation of negative social capital were identified which can cause, by way of the practice of participatory budgeting, the constraint of socio-spacial inequalities, the discouragement to participation, clientelist practices, group antagonism, depoliticization of the decision process, group monopolies, the exclusion or the self-exclusion of individuals in practice, and other constraints presented in this article. We don't intend to revoke the merits of $\mathrm{PB}$, much less that of social capital. We only seek to demonstrate that this capital is composed of two opposing faces.
\end{abstract}

Keywords: Participatory budgeting. Social capital. Constraint.

\section{INTRODUÇÃO}

$\mathrm{E}$ ste artigo pretende trazer uma contribuição para o debate em torno da análise dos impactos do capital social (CS) sobre as práticas de orçamentos participativos (OPs), dado que identificamos que existe uma supervalorização da ampliação do CS nas práticas de OPs, como se aquele fosse garantia para uma prática bem sucedida. A partir da contribuição de alguns autores selecionados, este artigo aponta que em determinadas circunstâncias o elevado estoque de CS pode provocar diversos constrangimentos à prática do OP. Sem ter a intenção de anular o mérito do OP, e muito menos do CS, este trabalho apresenta uma discussão sobre questões que merecem atenção e cuidados na efetivação de uma prática politizadora.

A literatura especializada tem apontado a participação social na gestão pública local como um grande instrumento pedagógico na construção de sujeitos politizados, assim como a ampliação da participação popular sobre os gastos públicos, especialmente destinados aos investimentos.

Para que o OP obtenha o sucesso esperado são necessários diversos aspectos, entre eles, a participação social e a politização da sociedade. A fim de analisar alguns 
pontos da participação dos indivíduos e as consequências sobre o desempenho do OP, recorremos especialmente ao conceito de capital social (CS), apresentado por Putnam (1996). Uma questão chave para a compreensão das ideias desenvolvidas por Putnam é a de indagar o que leva os indivíduos a colaborarem com a sociedade de forma eficiente. A resposta de Putnam é: possuir "capital social". 0 conceito de CS utilizado por este autor "diz respeito a características da organização social, como confiança, normas e sistemas, que contribuam para aumentar a eficiência da sociedade, facilitando as ações coordenadas" (PUTNAM, 1996, p. 177). Tratase de um bem público, por ser um atributo da cadeia social em que se insere 0 indivíduo.

Para Putnam o estoque de CS de uma sociedade é importante para que haja uma cooperação voluntária e consequentemente para o seu desenvolvimento. Tal estoque tende a inibir o oportunismo e a não-cooperação, uma vez que os indivíduos racionalmente tenderão a não descumprir as normas. A literatura aponta que o CS pode, igualmente, manifestar-se de forma negativa. Este artigo busca destacar alguns desses constrangimentos, especificamente nas práticas de OPs. Neste artigo, o termo "constrangimento" fará referência aos impedimentos de movimentos direcionados aos resultados louváveis, indicados pela literatura específica, os quais serão, brevemente, apresentados.

A fim de alcançar tal objetivo, foi realizada uma breve revisão crítica dos conceitos aqui utilizados a partir de alguns autores. A revisão de literatura em torno do conceito de Orçamento Participativo teve como base autores como Avritzer e Navarro (2003); Marquett (2007) e Pereira (2007). Para o aprofundamento do conceito de CS, buscaram-se as contribuições de Putnam (1996); D’Araujo (2003); Matos (2009); Bourdieu (1980); Fukuyama (1996); Portes (2000); Baquero, Souza e Scherer (2009). A seleção desses autores teve como critério a possibilidade de articular um diálogo capaz de construir e desconstruir ideias e apontamentos em torno da relação entre CS e OP.

\section{Delimitando os conceitos de OrÇamento Participativo e Capital Social}

Nesta seção, buscamos delimitar conceitualmente o OP e o que ficou conhecido como "capital social". Os trabalhos nacionais ligados à compreensão do fenômeno "Orçamento Participativo" são bem amplos, tanto em volume como em abordagens. Inicialmente buscamos apenas conceituar tal prática para tornar 
viável a proposta deste artigo. Em relação ao conceito de CS objetivamos delimitálo para tornar possível compreendermos sua origem e ampliação, especialmente no contexto do OP.

\section{O ORÇAMENTO PARTICIPATIVO}

De acordo com Azevedo (2003), existem basicamente três tipos de políticas públicas: i) redistributivas; ii) distributivas e; iii) regulatórias. 0 primeiro tipo diz respeito a políticas que têm por objetivo redistribuir a renda na forma de recursos e/ou financiamentos de equipamentos e serviços públicos. Esse tipo de política é popularmente chamada de "Política Robin Hood", e no qual o estrato social de alta renda da sociedade é financiador e os estratos de baixa renda são beneficiados. 0 segundo tipo são aquelas políticas que apresentam objetivos pontuais ligadas à oferta de equipamentos e serviços públicos. No que se refere ao financiamento, é a sociedade como um todo, através do orçamento público, que financia sua implementação, enquanto que os beneficiados são pequenos grupos ou pessoas individuais de diferentes estratos sociais. 0 terceiro tipo, política regulatória, está ligado à regulação de setores, referindo-se assim à legislação.

A partir das definições apontadas por Azevedo (2003), notamos que, grosso modo, o OP, de acordo com seus objetivos, caracteriza-se como um instrumento utilizado para a realização de política distributiva, buscando atender as áreas mais carentes de infraestrutura. Mas, isso dependerá, dentre diversos fatores práticos, da política regulatória que definirá a sua estrutura institucional, principalmente o critério de rateio dos recursos públicos destinados à execução do OP e da manifestação ou não dos constrangimentos do CS, como será apresentado posteriormente $^{2}$.

Embora a literatura tenda a apontar o caráter redistributivo do OP, sua existência não se pauta nesse aspecto, pois para uma redistribuição mais justa bastaria criar critérios técnicos eficientes, mesmo não participativos. 0 OP tem como ponto central a ampliação da cidadania e a maior politização das questões públicas.

\footnotetext{
${ }^{2}$ Por exemplo, Marquetti (2007) identificou que a prática do OP de Porto Alegre/RS tem canalizado prioritariamente os recursos públicos para áreas de baixo status. 0 mesmo não foi constatado por Bodart (2009), ao avaliar a prática realizada no município de Serra/ES. Assim, a prática do OP de Porto Alegre/RS, em seu resultado, apresentou-se como um instrumento de política redistributiva, enquanto que em Serra/ES se apresentou como uma política distributiva.
} 
Com relação à participação social, Azevedo (2003) aponta três tipos de associativismo: i) o "associativismo restrito ou societal", caracterizado por "não necessitar de contato com o poder público", como, por exemplo, o Rotary Clubes. ii) o "associativismo reivindicativo", que se caracteriza pelo seu caráter reivindicatório, como sugere seu nome e; iii) o "associativismo social clássico" (movimentos sociais), caracteriza-se pela associação em torno de valores. Desta forma, observamos que, geralmente, as práticas de OP se caracterizam como associativismo reivindicativo. No OP as reivindicações geralmente estão ligadas a melhorias urbanas e ofertas de equipamentos urbanos (AZEVED0, 2003), ou seja, a questões pontuais e momentâneas, o que é alvo de críticas (MARQUETTI; CAMPOS; PIRES, 2008, p. 24; SOUZA, 2001, p. 88).

De acordo com Azevedo (1991), podemos destacar dois tipos de participação social: a "Participação Restrita ou Instrumental" e a "Participação Ampliada ou Neocorporativas". A primeira se caracteriza por apresentar relação com um projeto específico e possuir um foco espacial. A segunda "diz respeito à definição de diretrizes gerais para as políticas públicas setoriais, tais como a política de saúde, a política de educação, os programas municipais, o plano diretor", referindo-se "à capacidade dos grupos de interesse de influenciar, direta ou indiretamente, as macroprioridades, diretrizes e a formulação, reestruturação ou implementação de programas e políticas públicas" (AZEVEDO, 2003, p. 19).

De forma geral, a participação social nas práticas do OPs, como no caso de Porto Alegre, vem se caracterizando por uma participação restrita, o que também tem sido alvo de crítica (AVRITZER; NAVARR0, 2003, p. 113; MARQUETTI; CAMPOS; PIRES, 2008, p. 22-25). Mas, como destacou Azevedo (2003, p. 7) um tipo de movimento pode se transformar em outro tipo por diversos motivos, assim como existem movimentos híbridos.

Grosso modo, o OP se apresenta como um mecanismo de democratização da política orçamentária pública, reunindo os cidadãos em assembléias públicas, nas quais estes avaliam a gestão municipal, elaboram propostas de acordo com suas demandas e deliberam sobre o uso e aplicação dos recursos. Aos dirigentes estatais resta executar a vontade popular, embora nem sempre isso ocorra. 0 OP se apresenta como uma forma institucional que envolve a partilha de espaços de deliberação entre representações estatais e as entidades da sociedade civil, tendo como base a negociação e a parceria (PEREIRA, 2007, p. 339). Leonardo Avritzer e Zander Navarro, propôs a seguinte definição para o OP: 
O OP é uma forma de rebalancear a articulação entre a democracia representativa e a democracia participativa baseada em quatro elementos: a primeira característica do OP é a cessão da soberania por aqueles que a detêm como resultado de um processo representativo local. [...]; em segundo lugar o OP implica a reintrodução de elementos de participação local, tais como assembléias regionais, e de elementos de delegação, tais como os conselhos [...]; em terceiro lugar, a participação envolve um conjunto de regras que são definidas pelos próprios participantes, vinculando o OP a uma tradição de reconstituição de uma gramática social participativa na qual as regras da deliberação são determinadas pelos próprios participantes; em quarto lugar, 0 OP se caracteriza por uma tentativa de reversão das prioridades de distribuição de recursos públicos a nível local através de uma fórmula técnica (AVRITZER; NAVARR0, 2003, p. 14-15).

Uma das características inovadoras do OP está no fato de possibilitar a presença de representações de diversos grupos sociais em um mesmo espaço democrático, discutindo interesses coletivos com o mesmo poder de voto (MARQUETTI; CAMPOS; PIRES, 2008). Embora, como destacou Pereira (2007), isso não garante a produção de um consenso entre os interesses coletivos.

\section{O CAPITAL SOCIAL}

De acordo com D’Araujo (2003), o conceito de Capital Social (CS) não é novo, porém, só tomou notoriedade a partir do livro de Robert Putnam, Making Democracy Work: Civic Tradition in Modern Italy, publicado em 1993.

Matos (2009a, p.34-35) afirma que a expressão "capital Social” parece ter sido empregada pela primeira vez por Hanifan (1916), que o havia definido como "um conjunto de relações sociais marcadas pela boa vontade, camaradagem e simpatia, atributos muito próximos do goodwill utilizado para definir as relações públicas na sua origem". Posteriormente, em 1961, o termo foi usado por Jane Jacobs, em sua obra Morte e vida de grandes cidades.

Foi com Pierre Bourdieu, em 1980, que o conceito surgiu de forma sistemática no campo da Sociologia. De acordo com Matos, Bourdieu em seupaper "Le capital social: notes provisoires", o definiu como "o conjunto de recursos atuais e potenciais que estão ligados à posse de uma rede durável de relações mais ou menos institucionalizadas de interconhecimento e inter-reconhecimento" (MATOS, 2009a, p. 35). 
Para Bourdieu (1980) o capital, em seu caráter utilitário, é um "ativo" social adquirido de forma desigual, uma vez que as redes sociais nas quais estão inseridos os indivíduos não oferecem as mesmas condições para obtenção das mesmas quantidades e qualidades desse capital.

Em 1993, Putnam afirmou que o conceito deCS "diz respeito a características da organização social, como confiança, normas e sistemas, que contribuam para aumentar a eficiência da sociedade, facilitando as ações coordenadas" (PUTNAM, 1996, p. 177). Trata-se de um bem público, por ser um atributo da cadeia social em que se insere o indivíduo. Para este autor, o CS é uma herança histórica, ou seja, é produzida e ampliada conforme as experiências dos grupos. Trata-se de um capital que quanto mais utilizado, mais a comunidade cívica o possuirá, uma vez que confiança gera confiança. De acordo com Putnam (1996), criar CS não é uma tarefa fácil, mas é fundamental para fazer a democracia funcionar. A confiança, para Putnam, é a base para a cooperação e esta gera confiança em um círculo virtuoso. É importante destacar que não se trata de uma confiança cega. Tal "confiança social pode manar de duas fontes conexas": as regras de reciprocidade e os sistemas de participação cívica (PUTNAM, 1996, p. 181).

Este autor afirma que o CS possibilita a existência de laços comunitários fortes capazes de garantir a ação coletiva, levando as pessoas à participação ativa no processo de construção da democracia, por meio de mecanismos não convencionais de envolvimento político (BAQUERO; SOUZA; SCHERER, 2009, p. 9). A regra de reciprocidade está relacionada, segundo Putnam, com o que dizia Cícero, no tempo de César: "nenhum dever é mais importante do que retribuir um favor". Para D'Araujo, isto tem a ver também com a ampliação de regras de constrangimentos social (D’ARAUJO, 2003, p. 18). É importante destacar que a ação dos sujeitos que detêm CS não são exclusivamente motivadas, em termos materiais, pelos ganhos da relação custo-benefício, uma vez que tais sujeitos podem agir por ações altruístas e princípios éticos.

Em relação ao sistema de participação cívica, este se relaciona à atuação dos indivíduos em vários tipos de associações, voluntárias ou não:

São participações em que cada um tem um grau de pertencimento e de importância relativamente igual e que possibilitam melhor informação, promovem as regras de reciprocidade, aumentam os custos potenciais de transgressão, redimensionam a confiança e possibilitam futuras colaborações (D’ARAUJ0, 2003, p. 19). 
De acordo como Fukuyama (2000 apud HIGGINS, 2005), o CS é produto espontâneo dos jogos repetitivos do dilema do prisioneiro. Uma vez que o jogo se repete, a simples estratégia de pagar na mesma moeda (cooperação por cooperação, traição por traição) conduzirá os jogadores racionais a um resultado de cooperação, produzindo assim o CS, uma vez que os indivíduos tenderão a apostarem em sua reputação de honestidade e de integridade.

Para Francis Fukuyama (1995 apud BAQUERO, SOUZA; SCHERER, 2009, p. 10), "o capital social pode simplesmente ser definido como a existência de certos conjuntos de normas e regras informais compartilhadas entre os membros de um grupo, que permite a cooperação entre eles". E ainda, Fukuyama (1996, p. 41) define CS como "capacidade que decorre da prevalência de confiança numa sociedade ou em certas partes dessa sociedade". Para este autor, o CS pode estar incorporado no menor grupo social (a família), bem como no maior de todos os grupos, a nação, assim como nos grupos intermediários (FUKUYAMA, 1996, p. 41). Diferentemente do capital humano, o CS, afirma este autor, é geralmente criado e transmitido por mecanismos culturais, como a religião, tradição ou hábitos históricos. Para Baquero, Souza e Scherer (2009, p. 10) o CS pode ser assim definido:

Em suma, o conceito de capital social será o resultado de um acúmulo de valores e condições historicamente construídas pelos grupos sociais, entre os quais estariam a confiança, a solidariedade, a cooperação sistêmica, a horizontalização das relações e uma intensa rede de trocas de informações que tornariam uma comunidade assim dinâmica.

Para Egidio Luiz Furlanetto (2008) o conceito de CS pode ser agrupado em duas correntes, como destacou:

[...] a primeira, comum entre os sociólogos, reforça a idéia de que as ações individuais podem ser fortalecidas por meio da participação dos mesmos em redes sociais, em interações diretas e indiretas com os outros atores da rede, e a relacionam aos recursos e benefícios potenciais que um ator detém, por possuir ou participar de uma rede sólida e durável de relações pessoais (Bourdieu, 1985; Coleman, 1988; Portes, 1998); na segunda corrente, a da preferência dos cientistas políticos, o capital social é visto como uma parte significativa das relações e laços internos que caracterizam as bases da ação coletiva e garantem-lhe a coesão necessária para atingir os resultados esperados (Putnam, 1993, p. 179; Fukuyama, 1995, p. 377; Locke, 1995, p. 3; Woolcock, 1998). (FURLANETTO, 2008, p. 62). 
Para outros autores o conceito de CS se mantém em uma perspectiva instrumental, "pois estaria baseada no proveito que os indivíduos obtêm ao participarem em estruturas sociais" (PONTES, 2000 apud HIGGINS, 2005, p. 31).

Baquero, Souza e Scherer (2009, p. 10) buscaram sintetizar as principais ideias, em torno do conceito de CS, da seguinte forma:

Subjacentes a essas definições identificam-se três ideias principais: (1) capital social gera externalidades positivas para os membros de um grupo; (2) essas externalidades são alcançadas por meio da confiança generalizada, normas e valores e seus efeitos nas expectativas e no comportamento; (3) confiança mútua, normas e valores surgem de formas informais de organizações com base em redes sociais e associações.

A grande dificuldade existente referente ao CS está em sua mensuração. "Várias metodologias têm sido propostas, especialmente por economistas, porém nada ainda parece consensual o bastante" (D’ARAUJ0, 2003, p. 27). A maior parte dos trabalhos tem buscado, sem muito rigor, medir os resultados do CS, mas não o CS em si. Como tais trabalhos tendem a identificar as virtudes desse tipo de capital, buscamos neste artigo apontar como o CS pode apresentar diversos tipos de constrangimentos.

\section{Capital Social: constrangIMENTOS NA PRÁTICA DO OrÇamento Participativo}

0 sucesso da prática do $\mathrm{OP}$ depende de vários fatores como, por exemplo, do interesse político, da capacidade orçamentária do município, do modelo estrutural, da capacidade deliberativa da sociedade e da interação cooperativa da sociedade civil (MARQUETTI, 2007; BOAS, 2007). É justamente a interação cooperativa, juntamente com outros fatores, que faz com que haja o desenvolvimento do CS e este, por sua vez, determine o grau de cooperação entre os indivíduos, em um círculo virtuoso ou vicioso, como apresentaremos a seguir.

Para Coelho e Favareto (2007), a participação e a deliberação social, por meio do OP, podem provocar um mecanismo causal vantajoso para 0 desenvolvimento do CS, pois com a participação e a deliberação ocorrendo há um estímulo para a inclusão de novos participantes e, posteriormente, um aumento na confiança dos envolvidos no processo deliberativo. Assim, a prática deliberativa pode produzir CS, embora a pré-existência de um histórico associativo contribua 
indiscutivelmente para o sucesso da democracia deliberativa (MARQUETTI, 2007; COELHO E FAVARETO, 2007).

Em todas as práticas de OP, nas que se busca o sucesso deste instrumento de gestão pública, o CS tem sido desejado. Isso ocorre porque o estoque de CS de uma sociedade é importante para que haja uma cooperação voluntária e consequentemente para o seu desenvolvimento (PUTNAM, 1996). Para Baquero, Souza e Scherer (2009, p. 9), "0 aspecto essencial do CS em relação à participação política dos cidadãos diz respeito ao estímulo que este fator pode ter na mobilização política". Desta forma, a existência de CS pode possibilitar existência de uma gestão participativa, seja ela consultiva ou deliberativa.

Existe, por parte de muitos estudiosos, um viés sociológico que vê emergir da sociabilidade coisas positivas; enquanto que as negativas são comumente associadas ao comportamento do homo economicus. Porém, práticas de sociabilidades, como o CS, podem produzir consequências menos desejáveis (PORTES, 2000, p. 146; MATOS, 2009b).

Como bem destacou Matos (2009a, p. 153; 2009b, p. 53), a literatura publicada sobre o CS se concentra na investigação de suas consequências positivas, ignorando os aspectos negativos existentes no CS. Matos (2009b, p. 54) destaca que um tipo de relação social pode ser boa em dado contexto e ruim em outro, ocorrendo o mesmo com a positividade ou a negatividade do CS. Ao desejar a ampliação do CS na prática do OP, muitos têm deixado de lado a preocupação e 0 devido cuidado com tais constrangimentos do CS. 0 capital social pode promover diversos benefícios, assim como colaborar para o desenvolvimento de instituições, mas desde que, como destacou Furlanetto (2008, p. 65), bem aproveitado. Destacaram Baquero, Souza e Scherer (2009, p. 9) que "existem inúmeros exemplos de construção da capital social negativo (a máfia, o partido nazista, grupos racistas, entre outros)".

De acordo com Portes (2000, p. 146), estudos recentes têm identificado pelo menos quatro consequências negativas do capital social, que preferimos chamar de constrangimentos: i) exclusão dos não membros; ii) normas de nivelamento descendente; iii) restrições à liberdade individual e; iv) exigências excessivas a membros do grupo. Buscaremos apresentar como tais constrangimentos podem vir a se manifestar sobre as práticas de $\mathrm{OP}$, assim como acrescentaremos outros possíveis constrangimentos - que vêm sendo chamados de capital social negativo. 
0 primeiro constrangimento apresentado por Portes (2000) está ligado à exclusão dos não membros. 0 mesmo CS que gera fortalecimento do grupo pode propiciar barreira para a inclusão de não membros na prática do OP. "A cultura de pertencimento a um grupo social também exclui e marginaliza os “outros”' (MATOS, 2009a, p. 162). Quando há o fortalecimento da confiança, por exemplo, de um grupo de indivíduos que jogam futebol no bairro, estes poderão tender a definir previamente sua prioridade em construir um campo de futebol e participar "em peso" da assembléia do bairro, desestimulando os indivíduos não organizados a participarem do processo, pois será mais provável que o campo de futebol seja a prioridade escolhida do que a de indivíduos isolados, uma vez que as escolhas são, geralmente, definidas por voto simples nas plenárias públicas. Essa mesma situação pode se repetir entre diversos grupos dotados de CS e interesses próprios como, por exemplo, entre comerciantes, associações de hoteleiros, clube de esportes, entre outros. Outra manifestação da exclusão pode ocorrer na escolha dos delegados, pois o grupo fechado com elevada capacidade de coordenação e cooperação pode impossibilitar a renovação dos representantes. Nessa direção, Baquero afirma que "tem sido comum estabelecer uma correlação entre CS e 0 potencial de construção de redes de exclusão" (BAQUERO, 2004, p. 6).

A segunda consequência negativa do CS, apresentada por Portes (2000), está ligada ao nivelamento descendente. Ao participarem das escolhas das obras destinadas ao OP, os grupos dotados de confiança e reciprocidade tenderão a ter que repartir os benefícios de forma mais homogênea, podendo impossibilitar 0 desenvolvimento de certas áreas, uma vez que quase sempre os recursos destinados ao OP não são suficientes para atender as demandas. Esta consequência negativa é, dependendo do ponto de vista, contestável, uma vez que o objetivo do OP é justamente reduzir as desigualdades sócio-espaciais. Mas, por outro lado, o desenvolvimento de algumas áreas da cidade como, por exemplo, pontos turísticos ou áreas de desenvolvimento econômico são essenciais para o posterior desenvolvimento das demais partes da cidade/região.

0 terceiro constrangimento do CS, destacado por Portes (2000), está ligado à limitação da liberdade individual. Com a ampliação do CS na prática do OP, os indivíduos, devido à lógica da reciprocidade, terão que abrir mão de suas escolhas individuais. Esse fator pode, a posteriori, desestimular seu interesse em participar do OP, uma vez que o OP é, pelo menos a princípio, um associativismo reivindicatório. A lógica da reciprocidade, como regra de retribuição de favor não corresponde à noção de politização. Nesse contexto, o que teremos será uma 
despolitização do processo do OP, prevalecendo as lealdades construídas e não a abertura de uma discussão politizada, que promova condições de fortalecimento e aprofundamento da prática cidadã.

0 quarto constrangimento está ligado ao peso da participação nas regras do jogo. A confiança e a reciprocidade proporcionam condições de existência de normas e regras de condutas que possibilitam a manutenção do CS. Mas, para alguns indivíduos, a ampliação do CS pode ter um efeito oposto. A obrigação de ter que participar dos fóruns do OP e agir de forma esperada pelos demais membros pode trazer um desestímulo à participação, isso por se tornarem exigências pesadas ao indivíduo. 0 custo social acaba sendo grande o suficiente para que o indivíduo racional queira não participar do processo, como prevê Olson (1999). Este autor se apóia no conceito de benefício coletivo como um "benefício indivisível", ou seja, aquele que uma vez consumido por um grupo não pode ser negado a uma pessoa deste grupo, mesmo que este não tenha se dedicado em sua obtenção.

Segundo Olson, o interesse comum dos membros de um grupo pela obtenção de um benefício coletivo nem sempre é suficiente para levar cada um deles a contribuir para a obtenção desse benefício. Existem circunstâncias nas que o indivíduo do grupo sabendo que o benefício coletivo não lhe será negado, independentemente de sua participação ou não (por se tratar de um bem coletivo), tenderá a se escusar, a fim de ampliar seu bem-estar, deixando que os demais paguem pelos custos de sua obtenção. É sabido que Olson não considera em seu raciocínio um contexto no qual exista CS, assim como a ação de sujeitos altruístas, mas é uma situação que não podemos desprezar, uma vez que o indivíduo pode julgar ser melhor agir pela lógica individualista e abrir mão de seu CS acumulado frente aos custos deste.

Somados aos constrangimentos apontados por Portes (2000), destacamos outros constrangimentos do CS (de alguma forma, correlacionados àqueles já apresentados), tendo nosso foco nas práticas de OPs que vêm sendo realizadas no Brasil. A maior parte desses constrangimentos está ligada à assimetria de desenvolvimento do CS destacada por Higgins (2005, p. 29), a qual pode gerar, basicamente, sete possíveis manifestações de constrangimentos correlacionados: a) manutenção e ampliação da segregação sócio-espacial; b) monopolização das decisões por parte de alguns grupos; c) novas práticas de clientelismo; d) manutenção do jogo anterior; e) despolitização da prática do OP; f) auto-exclusão dos indivíduos devido aos limites dos recursos financeiros destinados ao OP e; g) 
0 antagonismo entre bairros ou grupos. Buscaremos aqui descrever e exemplificar estes constrangimentos.

Com relação à manutenção e ampliação da segregação sócio-espacial recorremos às contribuições de Putnam (1996). Se para este autor a cooperação presente depende do CS acumulado ao longo da história, podemos levantar a seguinte questão: Todos os bairros de uma regional do OP têm o mesmo histórico? A resposta é negativa. Entendemos então que o CS é produzido e reproduzido de forma assimétrica entre as diversas regiões do espaço, seja ele urbano ou rural, logo, identificamos a primeira possível manifestação perversa do CS: a manutenção e ampliação da segregação sócio-espacial, uma vez que a participação dos moradores de cada bairro das plenárias e sua capacidade de se apresentar como grupo de pressão será heterogênea. 0 fenômeno pode ocorrer da seguinte forma: se uma regional do OP possui bairros nos quais o estoque de CS é assimétrico, o resultado das plenárias tenderá a ser vicioso. Como nas plenárias regionais são definidas onde e quais obras serão realizadas no ano seguinte, a existência de um estoque de CS desproporcional - entre os bairros ou grupos de interesses - pode provocar um efeito de "causação circular", em que as obras acabam sendo sempre canalizadas para o mesmo bairro ou para o benefício dos mesmos grupos, devido a sua maior participação e capacidade de pressionar o poder público em relação aos demais bairros ou grupos.

Com relação à monopolização das decisões por parte de alguns grupos, observamos que o CS pode ampliar a participação popular na elaboração do orçamento municipal - contribuindo, não só para uma maior distribuição de renda. No entanto, para minimizar os desperdícios de dinheiro público, reduzir ou eliminar certos fatores de má qualidade de vida e minimizar a corrupção (MARQUETTI, 2007) também se pode criar grupos com disparidade de estoque de CS, provocando, na plenária do OP, a monopolização das decisões por parte dos grupos de alto estoque de CS. Esse constrangimento pode se manifestar, pois, 0 espaço urbano é marcado pela existência de grupos de interesses mais organizados e dotados de maior estoque de CS do que outros, refletindo no estoque de confiança social e no estímulo à participação no OP. É muito comum encontrar grupos previamente organizados participando de fóruns de orçamentos participativos, como, por exemplo, associações de comerciantes, de corretores, de hoteleiros, entre outros. Estes podem ter suas escolhas predeterminadas. Assim o CS, nesse contexto, dificultará o beneficiamento da sociedade não organizada e não se caracterizará como um espaço político, em seu sentido mais amplo. 
0 CS pode promover novas práticas de clientelismo. Matos (2009a) aponta que as regiões onde o CS é fortalecido é possível notar que os cidadãos participam mais das questões públicas, exigindo mais das autoridades e se comunicam melhor com os governantes. Essa afirmativa é verdadeira, mas como o CS não se desenvolve de forma homogênea entre os grupos, existe o perigo de haver um fortalecimento de práticas clientelísticas, podendo estar presente em relações assimétricas de dominação, assim, como observa Ostrom (Apud MATOS, 2009b, p. 54), "o capital social pode ter um lado escuro". Na existência de assimetria na organização social, o executivo pode vir a atender prioritariamente os grupos dotados de maior estoque de CS, objetivando ter apoio eleitoreiro.

0 CS pode promover a manutenção do jogo anterior. Embora se observe que uma pré-existência de CS na implantação do OP é de grande importância para seu sucesso (MARQUETTI, 2007; COELHO; FAVARETO, 2007), igualmente é importante destacar que a existência de CS também pode ser determinante para seu fracasso. Existem municípios brasileiros, por exemplo, nos quais grupos fechados dotados de CS vêm se beneficiando das práticas de corrupção pública, repetindo o mesmo jogo a cada rodada. Nesses municípios, a prática do OP é minada a ponto de fracassar ou de não chegar a ser implementada. Uma nova forma de gestão, baseada na inclusão de outros indivíduos, nesses casos, não é bem-vinda, pois pode alterar as regras do jogo que já vem sendo jogado por esse(s) grupo(s). Há os casos do tráfico de droga e/ou de gangues que, como destacou Souza (2005, p. 4), impedem que fóruns do OP ocorram dentro de seu território, ou simplesmente impossibilitam a existência de um debate, estando tudo já previamente determinado e escolhido por tais grupos.

Outro constrangimento possível de ser destacado é o perigo de ocorrer uma despolitização da prática de OP. A ampliação das regras de solidariedade e reciprocidade pode propiciar um cenário sem conflitos, limitados por normas rígidas, no qual os acordos são pré-determinados, não dando espaço para novos debates e propostas, descaracterizando o sentido da plenária pública. Essa situação pode vir a desestimular a participação de indivíduos não organizados e não incluídos no grupo.

A auto-exclusão dos indivíduos, devido aos limites dos recursos financeiros destinados aos OPs, pode vir a ocorrer da seguinte maneira: a ampliação do estoque de CS ao promover maior participação social possibilita que os participantes percebam que os recursos públicos são escassos frente às demandas existentes, 0 
que é comum no Brasil (AVRITZER; NAVORRO, 2003, p. 72). Essa situação pode, ao contrário do esperado, minar os estímulos à participação (HIGGINS, 2005, p. 70). Para Olson (1999) a decisão de todo indivíduo racional sobre se irá ou não contribuir para a obtenção do benefício coletivo depende se os custos da ação forem inferiores aos benefícios alcançados e, nesse contexto, o indivíduo racional tenderá a não pagar pelos custos desproporcionais aos benefícios, prejudicando a prática do OP. Elster (1994, p. 41) aponta que a escolha racional não se caracteriza como um mecanismo infalível, pois um indivíduo racional escolhe com base em suas crenças que lhe indicam a "melhor escolha". Ou seja, o processo pode ser racional, mas, mesmo assim, não atingir a verdade. Agir racionalmente é fazer 0 melhor para si mesmo, afirma Elster (1994, p. 42).

Como já apresentado, o CS se manifesta através da confiança e reciprocidade. Geralmente, nos OPs essa confiança é no governo, na instituição e nos indivíduos participantes. Marquetti (2007) apontou que muitos dos participantes tendem a não participar mais do OP após terem suas demandas atendidas. A existência de CS pode possibilitar uma situação de colaboração entre os participantes, ao ponto de o indivíduo colaborar com as escolhas de demandas mais urgentes, movido pela expectativa de que ele poderá, posteriormente, ter sua demanda particular atendida. As sanções sociais (ou o medo de perder a confiança dos demais indivíduos na próxima rodada do jogo) tendem, igualmente, a induzir o indivíduo a continuar colaborado nos próximos fóruns do OP. Mas, o mesmo CS que pode promover a participação constante do indivíduo, pode também, devido à politização e à racionalidade, criar um cenário propício para que o indivíduo se escuse da participação, isso devido a julgar que os custos são superiores aos benefícios.

Em relação o antagonismo entre bairros ou grupos, podemos partir do seguinte raciocínio: se o CS é capaz de produzir um sentimento de pertencimento que venha a incentivar os indivíduos a se integrarem a sua comunidade de forma ativa na prática do OP, esse sentimento de pertencimento pode igualmente gerar rivalidade entre os bairros, o que os impossibilitará, por exemplo, de somar seus recursos para construir um bom posto de saúde. Pelo contrário, cada bairro estará reivindicando o seu, mesmo que os dois postos venham a ser construídos próximos um do outro, o que impossibilitará de ter um posto de saúde de melhor qualidade, além de maximizar os gastos públicos com pessoal. Desta forma, como apresentou Matos (2009a, p. 172), "a forte lealdade entre os membros de um grupo pode criar antagonismo com outros grupos". 
Esse constrangimento do CS é fruto de uma dimensão desejada: o empowerment social ${ }^{3}$, que, entre tantas consequências, promove a ampliação da auto-estima, da auto-afirmação e da confiança dos indivíduos (BAQUERO; BAQUE0; KEIL, 2010, p. 9). Diversos estudos apontam que o OP apresenta condições para um maior empowerment da sociedade civil, promovendo 0 surgimento de uma espécie de "quarto poder" que se apresentaria em articulação com os três poderes clássicos (BOAS, 2007, p. 380). Boas, portanto, destaca que esse mesmo processo, realizado em alguns municípios, pode também ser o terreno de reprodução de práticas clientelísticas.

Ainda nesse contexto, pode haver um cenário de cooperação de grupos fechados com 0 intuito de disputar tais recursos escassos, o que ampliaria as desigualdades sócio-espaciais urbanas. Como apresentou Olson (1999), os grupos menores tendem a ter maior adesão de seus membros, por vários fatores, entre eles, pelo fato de o benefício ser dividido por um número igualmente reduzido de participantes, sendo o benefício recebido significativo a cada membro. Para este autor, grupos grandes são mais susceptíveis de não atingirem seus objetivos, em função do benefício ser diluído a tal ponto que os custos da participação excedem os benefícios alcançados. Em suma, recursos escassos tenderão a serem alocados de forma díspar, beneficiando um pequeno grupo da sociedade. Partindo da ideia de Coase (1960), segundo a qual os indivíduos agem de forma a reduzir seus custos e obter ganhos, Olson (2001) aponta que para tal finalidade os indivíduos, se puderem, utilizarão de coerção para a obtenção de seus resultados. Desta forma, as relações de poder, ignoradas por Coase, são de grande importância para a compreensão da realidade. E, justamente por existir grupos mais dotados de CS do que outros, o uso da coerção e do "convencimento" não pode ser descartado, especialmente os "acordos entre bastidores".

A partir de alguns elementos - brevemente mencionados neste trabalho da teoria dos jogos e da teoria de escolha racional, podemos considerar que 0 acúmulo de CS pode propiciar ações monopolizadas, bem como a exclusão ou a auto-exclusão do indivíduo na prática do OP. Para Baquero, Souza e Scherer (2009, p. 9) "avaliar essas experiências [existência de capital social] é útil no sentido de saber em que condições o capital social pode produzir resultados indesejados para o crescimento democrático de uma nação". Desta forma, torna-se necessário

\footnotetext{
${ }^{3}$ Utilizamos aqui o conceito de empowerment social como um processo por meio do qual os indivíduos, grupos sociais e organizações adquirem controle sobre questões de seu interesse.
} 
considerar a possibilidade de desenvolvimento de CS, o que já será um significativo passo na busca desse instrumento de gestão pública, o OP, cujo objetivo é efetivar uma política redistributiva.

\section{Considerações Finais}

A temática capital social (CS) é de grande importância para o sucesso ou 0 insucesso da prática do OP. Tal importância se dá devido ao fato do CS apresentar virtudes e constrangimentos que precisam ser conhecidos, para que medidas de correção possam ser realizadas. Embora Putnam (1996) defenda que o CS seja necessário para a cooperação social e seu desenvolvimento, tal capital pode desenvolver situações perversas, como a exclusão dos não membros, a criação de normas de nivelamento descendente, restrições à liberdade individual, exigências excessivas a membros do grupo, monopolização das decisões por parte de alguns grupos, novas práticas de clientelismo, manutenção do jogo anterior, despolitização da prática do $\mathrm{OP}$, auto-exclusão dos indivíduos, o antagonismo entre bairros e a despolitização do processo decisório do OP.

0 conceito de CS abre para a análise do OP possibilidades de compreensão da cooperação social, assim como de não-cooperação, bastando para isso identificar suas virtudes e constrangimentos.

É importante reconhecer que a lógica da reciprocidade não é a única motivação para a ação em torno do bem comum. Muitas ações realizadas na prática do OP são motivadas por princípios éticos e altruístas. Acreditamos que tais princípios podem se desenvolver, juntamente com o CS, em um ambiente aberto às práticas da cidadania.

Os constrangimentos apontados neste artigo são comuns nas práticas de OPs. Criar um espaço capaz de politizar e conscientizar os sujeitos acerca da importância de colaboração no desenvolvimento social é sem dúvida uma tarefa árdua. É necessário superar a visão de que o CS, como sinônimo de confiança e reciprocidade, é suficiente para o sucesso das práticas democráticas. A reciprocidade e a racionalidade devem dar lugar a uma visão mais ampla de cidadania: a do altruísmo. Se por um lado, criar um espaço capaz de politizar e conscientizar os sujeitos da importância da colaboração no desenvolvimento social é considerado uma tarefa árdua, igualmente, muitos acharão que a superação da reciprocidade e de racionalidade pela visão altruísta é uma quimera. 
Tais constrangimentos não anulam os benefícios do CS apresentados pela literatura, mas, apenas evidenciam que tal capital tem dois lados. Ter consciência de tal realidade é o primeiro passo para neutralizar tais consequências indesejadas na prática do OP. Se não forem levados em consideração tais constrangimentos e se não forem tomados os devidos cuidados, o OP pode não caracterizar-se como um instrumento democrático de política redistributiva. Pior do que isso, pode despolitizar todo o processo participativo, que para nós é seu maior motivo de existência.

\section{REFERÊNCIA}

AVRITZER, Leonardo; NAVARR0, Zander (Org.). A inovação democrática no Brasil. São Paulo: Cortez, 2003.

AZEVEDO, Sergio de. Políticas públicas: discutindo modelos e alguns problemas de implementação. In: SANTOS JUNIOR, Orlando A. (Org.). Políticas públicas e gestão local. Rio de Janeiro: Fase, 2003, p. 38.

AZEVEDO, Sergio de; PRATES, Antonio Augusto. Planejamento participativo, movimentos sociais e ação coletiva. Ciências Sociais Hoje: ANPOCS, São Paulo, 1991.

BAQUER0, Marcello. Los dilemas de la construcción democrática en Brasil: como el capital social podría ayudar a establecer un nuevo contrato social. 2004. Disponível em: <http://www.corredordelasideas.org/docs/set_04/marcelo_ baquero.doc $>$ Acesso: 20 jun. 2010.

BAQUER0, Marcello; BAQUERO, Rute; KEIL, Ivete. Para além do capital social: juventude, empoderamento e cidadania. Disponível em: <http://www. capitalsocialsul.com.br/capitalsocialsul/desenvolvimentoregional/Grupo\%20 2/18.pdf> Acesso em: 20 jun. 2010.

BAQUERO, Marcelo; SOUZA, Bruno Mello; SCHERER, Rafael Sabini. Adesconfiança política e sua incidência na fragmentação da cultura política. In: II SEMINÁRIO NACIONAL DE CIÊNCIA POLÍTICA DA UFRGS: América Latina em Debate, 2., 2009, Porto Alegre. Anais... Porto Alegre, 2009. Disponível em: <http://www6.ufrgs.br/ sncp/>. Acesso em: 22 abr. 2010.

BOAS, Marie-Hélène Sa Vilas. A participação como recurso disputado: uma análise dos dispositivos participativos dirigidos às mulheres introduzidas em Recife. In: 
DAGNINO, Evelina; TATAGIBA, Luciana (Org.). Democracia, sociedade civil e participação. Chapecó: Argos, 2007. p. 379-394.

BODART, Cristiano das Neves. Alocação socioespacial dos recursos públicos por meio do orçamento participativo de Serra/ES. 2009. Dissertação (Mestrado em Planejamento Regional e Gestão de Cidades) - Universidade Cândido Mendes Campos. Campos dos Goytacazes, RJ, 2009.

BOURDIEU, Pierre. Le capital social: notes provisoires. Actes de la Recherche em Sciences Sociales, n. 31, p. 2-3, 1980. Disponível em: < http://www.persee.fr/ web/revues/home/prescript/article/arss_0335-5322_1980_num_31_1_2069?_ Prescripts_Search_isPortletOuvrage=false > Acesso em: 10 de abr. 2010.

COASE, Ronald H. El problema del costo social. The Journal of Law and Economics, Chicago, p. 1-44, out.1960.

COELHO, Vera Schattan P; FAVARETO, Arilson. Dilemas da participação e desenvolvimento territorial. In: DAGNINO, Evelina; TATAGIBA, Luciana (Org.). Democracia, sociedade civil e participação. Chapecó: Argos, 2007. pp. 97-126.

D’ARAUJO, Maria Celina. Capital social. Rio de Janeiro: Jorge Zahar, 2003.

ELSTER, Jon. Peças e engrenagens das ciências sociais. Tradução de: Antônio Transito. Rio de Janeiro: Relume-Dumará, 1994.

FUKUYAMA, Francis. Confiança: as virtudes sociais e a criação da prosperidade. Tradução de: Alberto Lopes. Rocco: Rio de Janeiro, 1996.

FURLANETTO, Egidio Luiz. Instituições e desenvolvimento econômico: a importância do capital social. Revista de Sociologia Política, Curitiba, v. 16. supl., p. 55-67, ago. 2008.

HANIFAN, Lyda J. The rural school community Center. Annals of the American Acadey of Political and Social Science. v. 67, n.1, p.130-8, 1916.

HIGGINS, Silvio Salej. Fundamentos teóricos do capital social. Chapecó: Argos, 2005.

MARQUETTI, Aldamir. Experiências de orçamento participativo no Brasil: uma proposta de classificação. In: DAGNINO, Evelina; TATAGIBA, Luciana (Org.). Democracia, sociedade civil e participação. Chapecó: Argos, 2007. p. 77-96.

MARQUETTI, Aldamir; CAMPOS, Geraldo Adriano de; PIRES, Roberto (Org.). Democracia participativa e redistribuição: análise de experiências do orçamento participativo. São Paulo: Xamã, 2008. 
MATOS, Heloiza. Capital Social e comunicação: interfaces e articulações. São Paulo: Summus, 2009a.

MATOS, Heloiza. 0 lado escuro do capital social: implicações sociais e políticas. Revista Libero, São Paulo, v. 12, n. 23, p. 53-62, jun. 2009b. Disponível em: $<$ http://www.facasper.com.br/rep_arquivos/2010/03/16/1268758057.pdf > . Acesso em: 15 jun. 2010.

OLSON, Mancur. A lógica da ação coletiva. Tradução de: Fabio Fernandez. São Paulo: Edusp, 1999.

OLSON, Mancur. Poder y prosperidad: La superación de las dictaduras cuministas y capitalistas. Madri: Siglo Veintiuno de España, 2001.

OSTR0M, Elionor. Capital social negativo ou perverso. Estudos Sociológicos, v.21, n.63, p.572-574. 2003 .

PEREIRA, Marcus Abílio Gomes. Modelos democráticos deliberativos e participativos: similitudes, diferenças e desafios. In: DAGNINO, Evelina; TATAGIBA, Luciana (Org.). Democracia, sociedade covil e participação. Chapecó: Argos, 2007.

PORTES, Alejandro. Capital social: origens e aplicações na sociologia contemporânea. Sociologia, Problemas e Práticas, Lisboa, n. 33, p.133-158, set. 2000. Disponível em: <http:/www.scielo.oces.mctes.pt/scielo.php?script=sci_ arttext\&pid=S0873-65292000000200007\&lng=pt\&nrm=iso > . ISSN 08736529>. Acesso em: 15 jun. 2010.

PUTNAM, Robert D. Comunidade e democracia: a experiência da Itália moderna. Tradução de: Luiz Alberto Monjardim. Rio de Janeiro: Fundação Getúlio Vargas, 1996.

SOUZA, Celina. Construção e consolidação de instituições democráticas: papel do orçamento participativo. São Paulo Perspectiva, v. 15, n. 4, p. 84-97, 2001. Disponível em: <http://www.scielo.br/scielo.php?pid=S010288392001000400010\&script=sci_arttext $>$. Acesso em: 25 jun. 2010.

SOUZA, Marcelo Lopes. De ilusão também se vive: caminhos e descaminhos da democratização do planejamento e da gestão urbanos no Brasil (1989-2004). In: ENCONTRO NACIONAL DE PÓS-GRADUAÇÃO E PESQUISA EM PLANEJAMENTO URBANO E REGIONAL/ANPUR, 11., 2005, Salvador. Anais... Salvador: ANPUR, 2005. 